\title{
Comparative assessment of two behavioural risk factors (physical inactivity and unhealthy diet) among obese Bengalee women in rural and urban areas of West Bengal, India
}

\section{Chaitali Bose}

Hooghly Mohsin College

Julekha Sultana

Hooghly Mohsin College

Oly Banerjee

Serampore College https://orcid.org/0000-0002-0810-0183

Siddhartha Singh

Serampore College

Sandip Mukherjee

Serampore College https://orcid.org/0000-0003-4176-3496

Alak Kumar Syamal ( $\square$ alaksyamal@gmail.com )

Hooghly Mohsin College https://orcid.org/0000-0001-7021-9313

\section{Research Article}

Keywords: adiposity, food habit, sedentarism, non communicable diseases

Posted Date: February 25th, 2022

DOI: https://doi.org/10.21203/rs.3.rs-1396329/v1

License: (c) (i) This work is licensed under a Creative Commons Attribution 4.0 International License.

Read Full License 


\section{Abstract}

\section{Background:}

Unhealthy diet and physical inactivity are the behavioural risks, closely associated with obesity which is a metabolic risk leading to the development of Non Communicable Diseases (NCDs). Dietary transition and sedentary living is also significant even in rural India which might be accountable to uprising NCDs there. So the aim of our study was to assess dietary pattern and unhealthy dietary factors, to determine the prevalence of physical inactivity among obese bengalee women in rural and urban areas of West Bengal

\section{Methods:}

This study was conducted in Hooghly district of West Bengal, India and 150 female subjects ( 75 from rural area and 75 from urban area) of 20-40 years age group were recruited for the study considering inclusion and exclusion criteria. Different physical and socio-demographic variables were measured and dietary information was collected using questionnaire. Global Physical Activity Questionnaire (GPAQ) was used to collect information about physical activities of the study participants. Different anthropometric parameters (body weight, height, Body Mass Index [BMI], waist circumference [WC], hip circumference $[\mathrm{HC}]$, waist to hip ratio $[\mathrm{WHR}]$ and waist to height ratio $[\mathrm{WHtR}]$ ) were measures as the strong prediction tools for assessing their risks related to NCDs.

\section{Results:}

We found that most of the daily energy comes from carbohydrate in the diet of both groups, consumption of food groups like animal protein and dairy products, fruits, visible fat and sugar were significantly higher in urban group whereas dietary fibre, green leafy and other vegetables, pulses and nuts intake was significantly high in rural group. Physical inactivity prevalence was $64 \%$ in rural and $78.7 \%$ in urban and there was significant difference between rural and urban group regard to all the anthropometric indices.

\section{Conclusions:}

In summary, the behavioural risk factors those were assessed are undoubtedly apprehensive and anthropometric indices are pointing out towards associated possible metabolic risks which were poorer in urban group than rural, so further clinical investigation along with proper intervention measure is indispensible.

\section{Introduction}

Unhealthy eating, physical inactivity and obesity are the trio, amongst many others to heighten the ubiquity of Non Communicable Diseases (NCDs) for the last few decades worldwide. Since the late nineteenth century the pattern of diseases and the cause of mortality of the then developed countries had started to take a shift from communicable infectious diseases to chronic diseases which were not infectious or transmissible (1).This epidemiological transition was the outcome of 'complex 
modernization' of those societies which also have had social, technological, economical and demographical transition leading to increase in life expectancy and simultaneous decrease in death rate. Like the other low or middle income counties, India is also a witness of such transition. Rapid modernization, urbanization, industrialization, fast progression of technology and medical science, improved hygiene and sanitation all boost up the socio-economic level, upraise the standard of living, pull the mortality down, take the life expectancy up and change the demography. And all these led to the development of 'Lifestyle Diseases' which are the by-products of 'fast- paced modern lifestyle'; the way people live their daily lives, adopt habits those belittle healthy living and head towards sedentary alive and lead to the development of different chronic medical problems. Lifestyle diseases are also called 'non communicable diseases' (NCDs) or 'disease of the civilization' (2). Such diseases slowly progress over years, chronic in nature and are the major reasons of adult deaths, diseases and functional impairments or disabilities across the world in the present era. According to report of World Health Organization (WHO), amongst all global deaths $71 \%$ is accountable to $\operatorname{NCDs}(3,4)$. As estimated that every year 15 million or more deaths happen due to NCDs is 'premature death' (i.e. death in between 3069 years) and $85 \%$ of such deaths occur in countries with low or middle socio-economic background. Disease burden of NCDs is rising by leaps and bounds every year in India as well. As per WHO report 2014, India contributes two- third of all deaths from NCDs occur in south East Asia region of world health organization. And in India, amidst all deaths, $60 \%$ death results from NCDs. And out of all deaths coming from NCDs in India, $45 \%$ comes from cardio-vascular (including heart diseases, stroke and hypertension) diseases, $22 \%$ is the contribution of chronic pulmonary diseases followed by different cancers $(12 \%)$ and $3 \%$ results from diabetes (5). The behavioural risk factors (unhealthy diet; physical inactivity; tobacco and alcohol consumption) interact with one's genetic make-up and lead to metabolic changes (obesity, raised blood sugar, hypertension and dyslipidemia) and provide the complex aetiology behind the commencement of NCDs (6). The scenario of NCDs among Indian is quite distressing. Age standardized prevalence of obesity, hypertension and hyperglycaemia have raised by $22 \%, 10 \%$ and $9 \%$ respectively among both sexes (age group $\geq 18$ years) within four years i.e. 2010-2014. Arokiasami (2018) published a report on increasing trends of NCDs in India and noted that in 2016 almost 4 million people in India have lost their lives by cardio-vascular and respiratory disease and then in diabetes. The mortality rates due to cardio-vascular diseases, chronic obstructive pulmonary disease and diabetes have escalated by $34.3 \%, 29.2 \%$ and $29.7 \%$ respectively from 1990 to 2016 in India. Mortality burden for diabetes was more prevalent in women (3.4\%) than men (2.9\%) (7). So, India which is facing 'double burden of diseases' (both non-communicable and infectious diseases), time to time monitoring and surveillances on the behavioural and metabolic risk factors among people residing in different states or regions of the country, are utmost important for making health care policies and programmes. In India many surveys have been carried out to assess the NCDs risk factors and Nethan et al. (2017) reviewed and produced a comprehensive report from the available data of different surveillances across the country and noted that as per National Family Health Survey (NFHS) prevalence of obesity and overweight has raised from 10.6-12.6\% among women from 1998-99 to 2005-06; Anjana et al. (2014) revealed 54.4\% Indians are physically inactive and it is more prevalent in urban than rural and among women than men; and urban people are more hypertensive than rural (8). According to NFHS-4 report, prevalence of overweight, 
obesity and hypertension raised hand in hand in both sexes. For women (age group 15-49 years) prevalence of hypertension and hyperglycaemia ranged from 8-18\% and 3\% to 11\% respectively (9). Sharma et al., based on NFHS-4 (2015-16) report observed that prevalence of having at least one NCD is higher among women than men and some other studies also showed that NCD burden is more upon women than men which may be due to the biological and social factors of women (10). So Indian women, who have been kept in the centre of Sustainable Development Growth (2015-30) need more surveillances to lessen their burden of NCDs.

West Bengal also follows the similar trends as prevalence of overweight or obesity in female has risen from 11.4\% (NFHS-3, 2005-6) to 19.9\% (NFHS-4, 2015-16). And in every cases urban women were more prevalent than rural (overweight or obesity in urban-30.6\%, rural - 15\%; mild \& very high hyperglycaemia in urban- $8.7 \%$ and $4.2 \%$ in rural-6.8\% and $3.2 \%$ ) mild, moderate and severe hypertension in urban-9.1\%, $2.1 \%$ and $0.8 \%$ in rural- $7.3 \%, 1.7 \%$ and $0.7 \%$ respectively) (9). So, the aim and objectives of this study is to assess dietary and physical activity pattern among obese women in both the selected rural and urban parts of West Bengal to make a comparison between these two groups regarding those behavioural factors and to make them aware about their health status and possible cardio-metabolic risks through the assessment of the anthropometric parameters amongst them.

\section{Materials And Methods}

This study was a community based cross sectional study of urban and rural areas of Hooghly district in West Bengal. Urban areas are the municipal areas and rural areas are the villages of gram panchayat under Community Development Block of the same districts. Municipal areas and villages were purposively selected based upon the distance, accessibility and familiarity of the researchers.Among municipal areas first wards then streets and in villages streets were chosen through simple random method and then subjects were chosen from the households on the streets by systematic random sampling based on the study criteria. As inclusion criteria, all the females were Bengalee (Hindu), permanent residents in those households, age group were 20-40 years and with a BMI between 25-30 $\mathrm{kg} / \mathrm{m}^{2}$ and free from any clinically diagnosed NCDs; also, they never consumed any form of tobacco or alcohol. As exclusion criteria, those, who were physically, mentally challenged or non-ambulatory; already suffering from chronic diseases or are on certain medications (like anti depressant, anti- hypertensive, contraceptives, steroids or others; underwent any surgery, on weight reduction therapy; pregnant, lactating or planning for conception were excluded.Total 150 (n) obese females were selected from both rural ( $n_{1}=$ 75) and urban $\left(n_{2}=75\right)$ areas. Background information like name, age, sex, residence, ethnicity, education, marital status, occupation, family income and size were collected. Modified B.G. Prasad scale 2019 was used to classify socio-economic classes of the subjects (11).

\section{Dietary information}

24 hour recall method on multiple, non-consecutive days was done avoiding days of fasting or feasting. Dietary diversity on week days or on weekends also considered. Subjects were asked to remember all 
foods and beverages starting from breakfast they had on the day before survey day. Standardised, measured and locally used utensils were utilized during survey. Ingredients used in every meal, foods that consumed outside and their portion size were also asked. Mean consumption of different nutrients and foods under various food groups were calculated using Diet Cal software (which used nutritive values of Indian foods). According to WHO diet low in fruits and vegetables ( $<400 \mathrm{gm} /$ day), high in saturated fat and dietary salt is considered as unhealthy diet.

\section{Physical activity}

Global Physical Activity Questionnaire (GPAQ), developed by WHO was used in the study to collect information on physical activities of subjects. This questionnaire involved three domains i.e. work, travel and recreation for assessing MET scores. Metabolic Equivalent (MET) is the ratio of an individual's metabolic rate during work and is relative to the person's resting metabolic rate.1MET = energy expenditure at sitting quietly and is equivalent to $1 \mathrm{kcal} / \mathrm{kg} / \mathrm{hour}$ calorie consumption. To determine the physical activity of the participants in the study, the mentioned guidelines were followed considering every domain and their sub domains of physical activity; 4 METs and 8 METs are assigned for time spends in moderate and vigorous intensity activities respectively; total time was measured which the participant had spent in all physical activities in a typical week, the intensity and the days were also considered. If an individual is involved in 75 minutes vigorous or 150 minutes moderate intensity activities across all the domains in a week or if the MET-minute value is 600 equivalent combination of both vigorous and moderate intensity activities in a week will be considered as physically active. Depending on MET scores/ week classification of physically inactive, active and highly active are:

$<600$ MET-minutes - Physically inactive

600-1200 MET-minutes - Physically active

>1200 MET-minutes- Highly active $(12,13)$

\section{Anthropometric Measurement}

Body weight, height, waist circumference (WC) and hip circumference $(\mathrm{HC})$ were measured using standardized protocols and instruments (14). Body Mass index (BMI), ratio of waist circumference to hip circumference and waist circumference to body height i.e. Waist to Hip Ratio (WHR) and Waist to Height Ratio (WHtR) were respectively calculated as well. BMI is used to categorize generalised obesity and is derived from dividing body weight ( $\mathrm{kg}$ ) by height (in meter squared) and when it is $\geq 25 \mathrm{~kg} / \mathrm{m}^{2}$ then the condition is considered as obesity for Asian-Indian. WC and WHR are more unique to detect abdominal obesity and WC $\geq 80 \mathrm{~cm}$ is considered as abdominal obesity, whereas WHR $<0.85$ is regarded as normal for Indian women (15).WHtR $>0.5$ is seen as strong predictor of cardio-metabolic risk in obesity (16).

\section{Ethical consideration}

The Human Ethical committee of Srerampore College in Hooghly district under university of Calcutta has approved the study design and protocols and written informed consent was obtained from each 
participant before the study.

\section{Statistical analysis}

Descriptive statistics like mean, standard deviation (SD) was done and to compare the mean values between the groups two tail, unpaired t-test was performed. When $p$ value was $<0.05$, difference was considered as significant (17).

\section{Result}

\section{Age group and residence wise distribution of selected subjects}

The mean age \pm SD of rural and urban female group was $35.7 \pm 10.3$ and $35.3 \pm 7$ respectively.Among rural women $44 \%$ and $56 \%$ belong to the age group of $20-35$ years and $36-50$ years whereas in urban it was $46.7 \%$ and $53.3 \%$ respectively. Table 1 shows the age wise distribution of samples between ruralurban areas.

Table 1

Age and residence wise distribution of subjects

\begin{tabular}{|lllll|}
\hline Age group & Rural $\left(n_{\mathbf{1}}=75\right)$ & $\%$ & Urban $\left(n_{2}=75\right)$ & $\%$ \\
\hline $20-35$ years & 33 & 44 & 35 & 46.7 \\
\hline $36-50$ years & 42 & 56 & 40 & 53.3 \\
\hline Mean age \pm SD & $35.7 \pm 10.3$ & & $35.3 \pm 6.97$ & \\
\hline
\end{tabular}


Table 2

Socio-demographic profile of rural and urban subjects

\begin{tabular}{|c|c|c|c|c|}
\hline \multirow[t]{2}{*}{ VARIABLES } & \multicolumn{2}{|c|}{$\operatorname{RURAL}\left(\mathrm{n}_{1}=75\right)$} & \multicolumn{2}{|c|}{ URBAN $\left(\mathrm{n}_{2}=75\right)$} \\
\hline & No & $\%$ & No & $\%$ \\
\hline \multicolumn{5}{|l|}{ Marital status } \\
\hline Ever married & 67 & 89.3 & 63 & 84 \\
\hline Unmarried & 8 & 10.7 & 12 & 16 \\
\hline \multicolumn{5}{|l|}{ Educational status } \\
\hline Primary schooling or less & 26 & 34.7 & 14 & 18.7 \\
\hline High schooling or above & 49 & 65.3 & 61 & 81.3 \\
\hline \multicolumn{5}{|l|}{ Occupation } \\
\hline Professionals/ skilled worker & 4 & 5.3 & 13 & 17.3 \\
\hline Semi-skilled workers & 13 & 17.4 & 19 & 25.3 \\
\hline Unskilled manual & 22 & 29.3 & 11 & 14.7 \\
\hline Housewife & 32 & 42.7 & 25 & 33.3 \\
\hline Student/ unemployed & 4 & 5.3 & 7 & 9.3 \\
\hline \multicolumn{5}{|l|}{ socio economic status } \\
\hline Upper & 5 & 6.7 & 17 & 22.7 \\
\hline Upper-middle & 17 & 22.7 & 26 & 34.7 \\
\hline Middle & 29 & 38.6 & 21 & 28 \\
\hline Lower-middle & 13 & 17.3 & 7 & 9.3 \\
\hline Lower & 11 & 14.7 & 4 & 5.3 \\
\hline
\end{tabular}

\section{Socio-demographic data}

Socio-demographic profile from both the areas was studied and observed that $89.3 \%$ rural and $84 \%$ urban females are ever married, higher percentage of urban females attended high schools or above $(81.3 \%)$ than rural females $(65.3 \%)$ whereas $18.7 \%$ and $34.7 \%$ had primary schooling or less among the urban and rural subjects respectively. In occupational sector, in urban group highest percentage of subjects was only housewife (33.3\%) whereas in rural areas mostly was involved in unskilled manual labours (38.7\%); percentage of those urban women engaged in semi-skilled, professional or skilled, unskilled labour and were student or unemployed are $25.3 \%, 17.3 \%, 14.7 \%$ and $9.3 \%$ respectively whereas in rural areas percentage of housewife is $30.7 \%$, semi-skilled workers is $20 \%$ and same percentage of rural females is 
seen in both skilled or professional and student/unemployed groups (5.3\%). According to socio-economic status, $22.7 \%$ and $6.7 \%$ belongs to upper class, $34.7 \%$ and $22.7 \%$ is in upper-middle class, $28 \%$ and $38.6 \%$ falls in middle class, $9.3 \%$ and $17.3 \%$ in lower middle and $5.3 \%$ and $14.7 \%$ in lower class among both the urban and rural groups respectively.

\section{Dietary profile}

In Table 3 Data analysed from collected information, revealed that mean intake of calorie/ day by rural subjects is $1941.5 \pm 168.9 \mathrm{kcal}$ and urban is $2027.4 \pm 166.3 \mathrm{kcal}$ and this difference is significant. In contrast, mean daily dietary fibre intake is significantly higher in rural females than their urban counterparts (19.5gm in rural and 16.5 in urban). Average daily consumption of different food groups was also calculated and it showed that there was no significant difference between both the groups regarding the mean consumption of whole and refined cereals and the root and tuber groups which is mostly potato ( $314.7 \mathrm{gm}$ and $310.2 \mathrm{gm}$ cereals and $100.2 \mathrm{gm}$ and $99.7 \mathrm{gm}$ root and tubers by rural and urban subjects respectively). But results revealed strong significant difference between these two groups in terms of having other food groups like dairy products and other animal protein food group ( $p$ value 0.000 ), visible fats ( $p$ value 0.003 ), fruits ( $p$ value 0.004 ) and added sugar ( $p$ value 0.01 ). In all cases consumption was significantly higher in urban group whereas when it comes to the mean daily intake of food groups like pulses ( $p$ value 0.02 ), green leafy vegetables or other vegetables $(p=0.000)$ and nuts and oil seeds $(p=0.001)$, rural women showed significantly higher intake than urban women. No significant difference was found between both the group regards to dietary salt intake (mean intake of rural subject $10.1 \pm 1.6 \mathrm{gm}$ and in urban $9.8 \pm 1.6 \mathrm{gm}$ ). 
Table 3

Average nutrient consumption of study participants

\begin{tabular}{|llll|}
\hline Variables & $\begin{array}{l}\text { Rural (Mean } \pm \\
\text { SD) }\end{array}$ & $\begin{array}{l}\text { Urban (Mean } \pm \\
\text { SD) }\end{array}$ & $\begin{array}{l}\text { Level of Significance ( } \\
\mathbf{0}\end{array}$ \\
\hline Calorie (Kcal) & $1941.5 \pm 168.9$ & $2027.4 \pm 166.3$ & 0.002 \\
\hline Dietary fibre (gm) & $19.5 \pm 5.5$ & $16.5 \pm 4.4$ & 0.0003 \\
\hline Consumption of food groups & & & \\
\hline $\begin{array}{l}\text { Whole grain + refined cereals } \\
\text { (gm) }\end{array}$ & $314.7 \pm 29.1$ & $310.2 \pm 21$ & $\geq 0.05$ \\
\hline Pulses (gm) & $30.3 \pm 4.7$ & $28 \pm 7.2$ & 0.02 \\
\hline Egg/meat/fish/poultry (gm) & $23.5 \pm 7.7$ & $30.6 \pm 10.3$ & 0.0000 \\
\hline Dairy products (gm) & $64.1 \pm 23.9$ & $84.2 \pm 23.4$ & 0.0000 \\
\hline Root \& tubers (gm) & $100.2 \pm 26.6$ & $99.7 \pm 9.9$ & $\geq 0.05$ \\
\hline Green leafy vegetables (gm) & $22.1 \pm 8.4$ & $15.7 \pm 8.4$ & 0.0000 \\
\hline Other vegetables(gm) & $74.1 \pm 10$ & $50.7 \pm 11.2$ & 0.0000 \\
\hline Fruits (gm) & $21.8 \pm 6.7$ & $25.2 \pm 7.3$ & 0.004 \\
\hline Visible fats \& oils & $38.7 \pm 7.4$ & $42.4 \pm 7.9$ & 0.003 \\
\hline Nuts\& oilseeds(gm) & $2.2 \pm 1$ & $1.7 \pm 1$ & 0.001 \\
\hline Added sugar (gm) & $31.5 \pm 6.2$ & $34.5 \pm 8.1$ & 0.01 \\
\hline Added Salt (gm) & $10.1 \pm 1.6$ & $9.8 \pm 1.6$ & $\geq 0.05$ \\
\hline
\end{tabular}

Not only the food groups but also the mean percentage of energy/day derived from macronutrients like carbohydrate (carb), protein, fat and saturated fat was studied in both the groups as well, which showed rural subjects derive more energy from carbohydrate than urban subjects. Figure 1 has represented the mean consumption of percentage of energy from those nutrients along with its SD values.

\section{Physical activity}

Data revealed that $64 \%$ of rural subjects and $78.7 \%$ of urban subjects are physically inactive i.e., MET scores was < 600; percentage of active females (MET score 600-1200) is 32 and 21.3 in rural and urban areas respectively; whereas only $4 \%$ rural female subjects are highly active (MET score $\geq 1200$ ) and unfortunately among urban subjects that is nil considering all the domains of activity, shown in Table 4. 
Table 4

Sample distribution on total energy expenditure on low/ moderate/ vigorous activity/week

\begin{tabular}{|lll|}
\hline MET VALUE & RURAL $\mathbf{n}_{\mathbf{1}}=\mathbf{7 5}(\%)$ & ${\text { URBAN } \mathbf{n}_{\mathbf{2}}=\mathbf{7 5}(\%)}$ \\
\hline PHYSICALLY INACTIVE $<600$ & $48(64 \%)$ & $59(78.7 \%)$ \\
\hline ACTIVE 600-1200 & $24(32 \%)$ & $16(21.3 \%)$ \\
\hline HIGHLY ACTIVE $\geq 1200$ & $3(4 \%)$ & 0 \\
\hline
\end{tabular}

Table 5 has depicted that among the subjects in both the areas prevalence of physical inactivity in particular domains were also assessed and it was found that among rural subjects, most was inactive in recreational domain (69.3\%) and lowest percentage of inactivity was seen in travel domain (50.6\%). On the other hand among urban female subjects mostly was inactive in occupational domain (76\%) and least in travel domain (58.7\%).

Table 5

Percentage of sample (rural and urban) physically inactive in the following domains

\begin{tabular}{|lllll|}
\hline DOMAIN & RURAL & \multicolumn{3}{c|}{ URBAN } \\
\cline { 2 - 5 } & $\mathbf{n}_{\mathbf{1}}=\mathbf{7 5}$ & $\mathbf{( \% )}$ & $\mathbf{n}_{\mathbf{2}}=\mathbf{7 5}$ & $\mathbf{( \% )}$ \\
\hline WORK & 45 & 60 & 57 & 76 \\
\hline TRAVEL & 38 & 50.6 & 44 & 58.7 \\
\hline RECREATION & 52 & 69.3 & 49 & 65.3 \\
\hline
\end{tabular}

Though higher percentage of female subjects in rural area showed inactivity in their leisure than the urban females but when it was studied according to the age group (20-35 yrs and 36-50 yrs) it indicated that subjects belong to the 36-50 year of age group was more inactive than the age group of 20-35 yrs in both the areas, shown in Fig. 2.

In Table 6 the mean time/ day spend on various domains with vigorous to moderate intensity activity was calculated and whether the differences on that time spent between both groups is significant or not was tested too. No significant differences were found regard to mean time spent on vigorous work and recreation but differences were significant in terms of travel and moderate intensity occupational work domains. Urban obese subjects spend more time on sitting than rural and the difference was significant ( $p$ value $=0.03$ ) 
Table 6

Mean time spend on different activities/day (Mean \pm SD) and level of significance

\begin{tabular}{|lllll|}
\hline \multirow{2}{*}{ ACTIVITY } & DOMAIN & \multicolumn{3}{l}{} \\
\cline { 3 - 5 } & & Rural & Urban & Level of Significance $(<\mathbf{0 . 0 5})$ \\
\hline \multirow{2}{*}{ VIGOROUS } & WORK & $9.61 \pm 40.1$ & $1.4 \pm 3.21$ & $\geq 0.05$ \\
\cline { 2 - 5 } & RECREATION & $0.61 \pm 1.9$ & $0.83 \pm 1.64$ & $\geq 0.05$ \\
\hline \multirow{2}{*}{ MODERATE } & WORK & $16.6 \pm 35.6$ & $6.5 \pm 12.3$ & 0.02 \\
\cline { 2 - 5 } & TRAVEL & $8.9 \pm 10.1$ & $5 \pm 6.8$ & 0.005 \\
\cline { 2 - 5 } & RECREATION & $3.09 \pm 5.4$ & $3.12 \pm 5.1$ & $\geq 0.05$ \\
\hline
\end{tabular}

\section{Anthropometric profile}

Table 7 has expressed the anthropometric indices of both the groups and indicated that in every parameter urban obese female subjects had significantly higher values than their rural counterparts. Body weight and BMI which indicates generalised obesity was $71.6 \mathrm{~kg}$ and $28\left(\mathrm{~kg} / \mathrm{m}^{2}\right)$ in urban and $69.5 \mathrm{~kg}$ and $27.4\left(\mathrm{~kg} / \mathrm{m}^{2}\right)$ in rural females. WC and WHR i.e. indicators of abdominal obesity was also significantly higher in urban group. WHtR was $0.57 \pm 0.02$ for rural and $0.58 \pm 0.02$ for urban group and was significantly different ( $p$ value 0.04 ).

Table 7

Anthropometric profile of rural and urban samples (Mean \pm SD)

\begin{tabular}{|llll|}
\hline Variables & RURAL & URBAN & Level of significance $<0.05$ \\
\hline Body weight $(\mathrm{kg})$ & $69.5 \pm 5.05$ & $71.6 \pm 5.9$ & 0.01 \\
\hline BMI $\left(\mathrm{kg} / \mathrm{m}^{2}\right)$ & $27.4 \pm 1.4$ & $28 \pm 1.6$ & 0.008 \\
\hline WC $(\mathrm{cm})$ & $91.7 \pm 3.4$ & $93 \pm 3.4$ & 0.02 \\
\hline WHR & $0.89 \pm 0.02$ & $0.9 \pm 0.02$ & 0.000 \\
\hline WHtR & $0.57 \pm 0.02$ & $0.58 \pm 0.02$ & 0.04 \\
\hline
\end{tabular}

\section{Discussion}

In our study, two major behavioural factors like unhealthy diet and physical inactivity of NCDs along with anthropometric parameters among the obese Bengalee women (20-50 years of age) from selected parts of both rural and urban groups were studied. And the overall view that has been emerged is utterly dreadful. 
Like other developing countries, India has been a witness to dietary transition as a consequence of urbanization, industrialization and globalization. Changed dietary pattern has been observed even among the rural residents; easily accessibilities to fast foods/junk foods/ready to cook or eat foods have displaced the traditional food consumption pattern in India(18-20). Numerous studies have been done on changed dietary pattern of Indians and all of these noted that consumption of dietary fibre, fruits and vegetables are gradually decreasing whereas intake of visible fats and added sugar are escalating rapidly (21).

In this study, researchers have also found such similarities in the dietary pattern of both rural and urban groups which was characterised by low intake of fruits, vegetables but high intake of dietary fat and sugar. Consumption of plant and animal protein was lower than the recommended value in both groups. Urban obese group was having more animal protein, dairy products, fruits, visible fat and oil and added sugar than rural group whereas rural group was consuming more pulses, green leafy and other vegetables and nuts and oil seeds. And these differences were significant, on the other hand there was no such differences regard to the cereals, root and tubers which was mainly potato and in salt consumption between the both groups.

Our study revealed that most of the daily energy is coming from carbohydrate, a reason behind increasing diabetes in India and consumption of poor amount of vegetables and fruits and increased amount of cereals indicate that those subjects' diets are greatly unhealthy (22-25).

Poor consumption of dairy products and animal protein especially in rural group which is observed in this study differs from the observations of Shetty (2002) (21).But the study made by Sharma et al.(2020) that compared Indian diet considering all the districts and the rural-urban areas in India with the recommendation made by Eat-Lancet, mentioned that calorie intake from protein from both the animal and plant sources is quite below the referred range and in rural diet only $6 \%$ of energy comes from protein, which is similar to our findings. This study also put forward that low intake of whole cereals, fruits and vegetables except potato and high intake of fat, added sugar and salt is the cause behind the escalating NCD burden of India (26).

A cross-sectional study on rural, urban and migrants in the industrial areas of four large cities in India found that $\%$ of energy from nutrients in both rural and urban females were $63.9 \%$ and $62.6 \%$ from carbohydrate, $10.7 \%$ and $11.3 \%$ from protein, $24.9 \%$ and $26.4 \%$ from fat and $7.3 \%$ and $7.9 \%$ from saturated fat respectively. Except carbohydrate all the values were higher than our study. But in connection to food group consumption showed similar results i.e. fruits and vegetables, dairy products and meat intake were significantly higher in urban female group than the rural group (27). Rural-urban difference in dietary pattern among ever married women in Orissa, pointed out higher percentage of women (age-15-49 years) with $\mathrm{BMI}>18.5$ from urban area were consuming fruits, green leafy and other vegetables, dairy products and animal protein than their rural counterpart. And also more percentage of urban female was vegetarian than rural which may be a reason behind their high consumption of vegetables (28). Dietary and nutrient intake by urban females (mean age $45.8 \pm 9.8$ ) in a North Indian 
study noted urban diet was low in cereal, pulses, fruits and vegetables but rich in saturated fat, tran fat and total fat than the recommended values (29). ICMR-NIN (2020) reports on 'what India eats', showed that almost $97 \%$ in rural and $69.8 \%$ in urban region consume more than recommended amount of cereals and overall poor intake of fruits and vegetables and dairy products irrespective to sex and regions of India is the reason behind the elevated events of diabetes and hypertension accordingly. It also remarked that refined cereals and carbohydrates are contributing highest amount of energy to meet their daily energy needs (22). Another study in south India by Sowmya et al. (2016), where 58\% of participants were women, aged over 20 years, unveiled similar findings that most energy is coming from cereal group and carbohydrate and less from fat and also noted low intake of fruits, vegetables, dietary fibre, tubers and sugar (30). Survey conducted by National Nutrition Monitoring Bureau (NNMB) 2017 on urban male and females in all states, concluded that people of both sexes consume a bulk amount of cereals and lower amount of fruits, vegetables and dairy products which was prevalent in all states but in few states including West Bengal tuber (mainly potato) consumption was very high (31). Many STEP-studies have been done in various parts of India on both sexes of rural and urban areas in different times which also put forward similar findings in terms of consumption of fruits and vegetables (as selected indicator of NCDs) and amongst almost all cases rural intake of fruits and vegetables were less than urban (32-35).

Physical activity which has been measured in this study, another behavioural risk factor for lifestyle diseases was also not satisfactory as well. More than half of all subjects, in both groups were inactive i.e. MET score $<600$. Urban obese women were more inactive $(78.7 \%)$ than rural group $(64 \%)$. Only $4 \%$ among rural subjects were only highly active whereas it was 0 in urban. This observation may be due to our selection of only obese female group. Across all the domains, urban subjects were mostly inactive in occupational domain whereas highest percentage of inactivity among rural subjects was found in recreational domain. Mean time/day spent on different sub-domains were also recorded and expressed that rural group spent only 9.6 minutes in vigorous work, 16.6 minutes in moderate work whereas it were 1.4 minutes and 6.5 minutes respectively for urban group. In travel domain it was 8.9 minutes and 5 minutes for rural and urban group respectively and was significantly higher in rural group but regarding recreation in both the sub domains (vigorous and moderate) no such differences was noted. Age group wise (20-35 years \& 36-50 years) participation in leisure activity was measured and emerged that older age group was less active in leisure among both the groups.

Ample researches have been done on physical activity pattern on both the sexes among adults in different regions covering both the rural-urban parts across India and most of them specified more physical inactivity amongst urban females than their rural counterparts, which also goes with our observation. ICMR-INDIAB (2014) studied on different states and rural-urban areas there in, showed $59.6 \%$ of rural female and $71.2 \%$ of urban females were inactive whereas only $12.6 \%$ and $5.8 \%$ were highly active from selected rural and urban India respectively. Among urban areas, highest percentage of women from Chandigarh were physically inactive (83.2\% in urban and $75.1 \%$ in rural) and least from Jharkhand (55.3\% from urban and $44.2 \%$ from rural). And mean time spent/day on moderate to vigorous physical activity (MVPA) among all domains indicated that females in Tamilnadu spent least time in work domain (25.7 minutes) and highest was in Maharashtra (43.5 minutes), whereas in travel and 
leisure domains Tamilnadu spent lowest time in a day (11.6 minutes and 12.7 minutes respectively). This study also showed activity in recreational domain gradually decreases with increase in age and was alike our report (36). Study of Shah and Mathur (2010) surveyed the prevalence of cardio vascular risk factors in India based on ICMR surveillance reports and noted that higher number of urban females were more inactive in work and travel domain whereas rural females were more inactive in leisure domain (37). Another South Indian study revealed that only $14 \%$ urban females were highly active whereas $50.7 \%$ females were engaged in the same from rural area (38). Mathew et al. (2009) in their study in South India on difference of physical activity among women in rural and urban areas produced the similar results as well (39).Tripathy et al. (2016), studied rural-urban differences regarding diet, physical activity and obesity on both male and female in North India (Punjab) and unveiled that $27.4 \%, 24.1 \%, 94.3 \%$ urban females and $24.7 \%, 32.8 \%, 95.2 \%$ of rural females were inactive in work, travel and recreational domain accordingly. But there no significant differences were found between rural and urban females regarding daily mean time spent on three domains and that is contrast to our study but such result might be due to selection of areas or the subjects (40). And that result also differed from other studies in South India, like Devamani et al. 2019 showed inactivity of urban females were (70.8\%) far above than rural group or the report of Newtonraj et al. (2019) which again noted lesser percentage of physical inactivity in rural females than urban which was $22.5 \%$, almost comparable to the prevalence of global physical inactivity i.e. $27.5 \%(41-43)$.

The subjects those who were chosen from both the rural and urban areas, were obese i.e. BMl $>25 \mathrm{~kg} / \mathrm{m}^{2}$. So the mean value of various anthropometric indices measured would definitely be higher when compared to general groups. Though we haven't studied or compared obesity prevalence between selected rural-urban females but all the anthropometric parameters those have been studied [like body weight $(\mathrm{kg}), \mathrm{BMI}\left(\mathrm{kg} / \mathrm{m}^{2}\right), \mathrm{WC}(\mathrm{cm}), \mathrm{WHR}, \mathrm{WHtR}$ ] were significantly higher in urban obese females than their rural counterparts. And we hypothesised such lofty parameters are indicators of different health issues like cardio-vascular diseases, insulin resistance, diabetes mellitus, metabolic syndrome, reproductive hassles, different cancer and so on among both the groups.

Copious studies have been done on obesity prevalence between rural-urban groups in different regions, which remarked that the anthropometric indices were higher in most cases among urban group than rural ones $(44,45)$. Increased body weight and BMI are the yardsticks for generalised obesity and is significantly correlated to different NCDs like asthma, hypertension, dyslipidemia, metabolic syndrome and others as studied in women (46-49). For Indian women $W C>80 \mathrm{~cm}$ and WHR $>0.85$ is considered as abdominal obesity and significantly associated with cardiovascular problems, diabetes, metabolic syndrome, pulmonary disorders, osteo-arthritis, reproductive problems and so on $(50,51)$. Midha et al. 2014 decided WC $>78 \mathrm{~cm}$ in women as a cut off for hypertension among Indian (52). WHtR which is now considered a better predictor of NCDs was found high in obese females and associated with different health issues $(53-56)$ including other sever infectious diseases $(57,58)$.

\section{Limitation of the study}


The sample size included in the study was not enough to comment on generalised population as we only consider the obese group. The data which have been considered are self-reported so any fabrication can mislead the investigation. Though we predict the possible health risks but due to shortage of resources we could not do biochemical investigation as it may depict explicit picture of the situation studied.

\section{Conclusion}

In the present study, dietary pattern, physical activity profile of obese bengalee female from both rural and urban sectors of the selected parts of West Bengal were assessed. The result showed presence of unhealthy diet in both the rural-urban groups whereas physical activity profile was worse in urban females than the rural group. The anthropometric parameters though were more heightened in urban group but were also dangerous enough even in the rural group to predict their associated clinically undiagnosed health risks and need to undergo clinical investigations. Lifestyle modification through dietary intervention and recommendation of enough physical activity can be beneficial to cut down the risk factors which could be investigated in future as well.

\section{Abbreviations}

NCD

Non communicable diseases

WC

Waist circumference

$\mathrm{HC}$

Hip circumference

WHR

Waist to Hip Ratio

WHtR

Waist to Height Ratio

MET

Metabolic Equivalent

GPAQ

Global Physical Activity Questionnaire

NFHS

National Family Health Survey

\section{Declarations}

\section{Conflict of interest:}

Authors declare no conflict of interest. 
Funding (information that explains whether and by whom the research was supported): No funding source available

Conflicts of interest/Competing interests (include appropriate disclosures): Authors declare no conflict of interest.

Ethics approval (include appropriate approvals or waivers): Included

Consent to participate (include appropriate consent statements): Consent were taken

Consent for publication (consent statement regarding publishing an individual's data or image): Consent were taken

Availability of data and material (data transparency): Data available and will be provided on request

Code availability (software application or custom code): Not Applicable

\section{Authors' contributions:}

Chaitali Bose: Conceptualization, data collection, data analyses

Julekha Sultana: Literature management, data collection

Oly Banerjee: Data collection, data management, statistical analysis

Siddharth Singh: Writing original draft, statistical analysis

Sandip Mukherre: Conceptualization, writing original draft

Alak K. Syamal: Conceptualization, Supervision, writing original draft.

\section{References}

1. McKeown, R.E. (2009). The epidemiologic transition: changing patterns of mortality and population dynamics. American Journal of Lifestyle Medicine, 3(1_suppl), 19S-26S.

2. Yadav, S., \& Arokiasamy, P. (2014). Understanding epidemiological transition in India. Global Health Action, 7(1), 23248.

3. Tabish, S.A. (2017). Lifestyle diseases: consequences, characteristics, causes and control. Journal of Cardiology \& Current Research, 9(3), 00326.

4. GBD 2015 Risk Factors Collaborators. Global, regional, and national comparative risk assessment of 79 behavioural, environmental and occupational, and metabolic risks or clusters of risks, 1990 2015: a systematic analysis for the Global Burden of Disease Study 2015, Lancet, 2016, 388(10053), 1659-1724. 
5. World Health Organization. Burden of NCDs and their risk factors in India (Excerpted from Global Status Report on NCDs-2014), 2019. Retrieved from https://www.who.int/docs/defaultsource/searo/india/health-topic-pdf/noncommunicable-diseases/ncd-situation-global-report-ncds2014.pdf?sfvrsn=ee0a9307_2

6. Esmailnasab, N., Moradi, G., \&Delaveri, A. (2012). Risk factors of non-communicable diseases and metabolic syndrome. Iranian Journal of Public Health, 41(7), 77.

7. Arokiasamy, P. (2018). India's escalating burden of non-communicable diseases. The Lancet Global Health, 6(12), e1262-e1263.

8. Nethan, S., Sinha, D., \&Mehrotra, R. (2017). Non communicable disease risk factors and their trends in India. Asian Pacific Journal of Cancer Prevention, 18(7), 2005.

9. NFHS-4. National Family Health Survey, (2015-16), India fact sheet, International Institute for Population Sciences (IIPS) \& Macro International. Mumbai: IIPS; 2017.

10. Sharma, S.K., Vishwakarma, D., \&Puri, P. (2020). Gender disparities in the burden of noncommunicable diseases in India: evidence from the cross-sectional study. Clinical Epidemiology and Global Health, 8(2), 544-549.

11. Pandey, V.K., Aggarwal, P., \&Kakkar, R. (2019). Modified BG prasad socio-economic classification, update-2019. Indian Journal of Community Health, 31(1), 150-152.

12. World Health Organization. Global physical activity questionnaire (GPAQ) analysis guide, Geneva: World Health Organization, 2012, 1-22. Available from: http://www.who.int/chp/steps/resources/GPAQ_Analysis_Guide.pdf

13. Bull, FC., Maslin, TS., \&Armstrong, T. (2009). Global physical activity questionnaire (GPAQ): nine country reliability and validity study. Journal of Physical Activity \& Health, 1;6(6), 790-804

14. Sengupta, P., Chaudhuri, P. \& Bhattacharya, K. (2013). Screening obesity by direct and derived anthropometric indices with evaluation of physical efficiency among female college students of Kolkata. Annals of Medical and Health Sciences Research, 3(4), 517-522.

15. Vasanthakumar, J.,\&Kambar, S. (2020). Prevalence of obesity among type 2 diabetes mellitus patients in urban areas of Belagavi. Indian Journal of Health Sciences and Biomedical Research, 13(1), 21.

16. Rajput, R., Rajput, M., Bairwa, M., Singh, J., Saini, O., \& Shankar, V. (2014). Waist height ratio: A universal screening tool for prediction of metabolic syndrome in urban and rural population of Haryana. Indian Journal of Endocrinology and Metabolism, 18(3), 394.

17. Bhattacharya, K., Kulshreshtha, R., Barman, S.S., \&Bhaduri, D. (2018). Assessment of physiological health status in relations to different anthropometric and Cardio-Respiratory measures of HeadSupported load carrying female porters of Sikkim, India. Research Journal of Pharmacy and Technology, 11(5), 1990-1995.

18. Satija, A., Hu, F.B., Bowen, L., Bharathi, A.V., Vaz, M., \&Prabhakaran, D., et al. (2015). Dietary patterns in India and their association with obesity and central obesity. Public Health Nutrition, 18(16), 30313041. 
19. Green, R., Milner, J., Joy, E.J., Agrawal, S., \&Dangour, A.D. (2016). Dietary patterns in India: a systematic review. British Journal of Nutrition, 116(1), 142-148.

20. Al Shamsi, H.S., Almutairi, A.G. \& Al Mashrafi, S.S. (2018). Food and Nutrition Systems in India Change as a Result of the Nutrition Transition: The Implications on the Food and Nutrition System in Relating to Changes in the Food Supply and Dietary Intakes. Global Journal of Health Science, 10(9), 1-74.

21. Shetty, P. S. (2002). Nutrition transition in India. Public Health Nutrition, 5(1A), 175-182.

22. ICMR-NIN. What India eats, ICMR-National Institute of Nutrition, Department of Health Research Ministry of Health and Family Welfare, Government of India, Hyderabad, India, 2020 Retrieve on 10/06/2021 https://www.nin.res.in/nutrition2020/what_india_eats.pdf

23. Gulati, S., \&Misra, A. (2014). Sugar intake, obesity, and diabetes in India. Nutrients, 6(12), 5955-5974.

24. Sami, W., Ansari, T., Butt, N.S., \&Ab Hamid, M.R. (2017). Effect of diet on type 2 diabetes mellitus: A review. International Journal of Health Sciences, 11(2), 65-71.

25. Mohan, V., Unnikrishnan, R., Shobana, S., Malavika, M., Anjana, R.M.,\&Sudha, V. (2018). Are excess carbohydrates the main link to diabetes \& its complications in Asians?. The Indian Journal of Medical Research, 148(5), 531-538.

26. Sharma, M., Kishore, A., Roy, D., \& Joshi, K. (2020). A comparison of the Indian diet with the EATLancet reference diet. BMC Public Health, 20(1), 1-13.

27. Bowen, L., Ebrahim, S., De Stavola, B., Ness, A., Kinra, S., \&Bharathi, A.V., et al. (2011). Dietary intake and rural-urban migration in India: a cross-sectional study. PloS One, 6(6), e14822.

28. Rout, N.R. (2009). Food consumption pattern and nutritional status of women in Orissa: A rural-urban differential. Journal of Human Ecology, 25(3), 179-185.

29. Agrawal, A., \&Varma, K. (2016). Diet and nutrient intakes in urban women of Rajasthan State, Northern India. Ecology of Food and Nutrition, 55(1), 16-29.

30. Sowmya, N., Lakshmipriya, N., Arumugam, K., Venkatachalam, S., Vijayalakshmi, P., Ruchi, V., \&Geetha, G. (2016). Comparison of dietary profile of a rural south Indian population with the current dietary recommendations for prevention of non-communicable diseases (CURES 147). The Indian Journal of Medical Research, 144(1), 112.

31. National Nutrition Monitoring Bureau Technical Report No 27 on Diet and Nutritional Status of Urban Population in India and Prevalence of Obesity, Hypertension, Diabetes and Hyperlipidemia in Urban Men and Women, 2017, Accessed from https://www.nin.res.in/downloads/NNMB\%20Urban\%20Nutrition\%20Report\%20Brief\%20\%20\%20report.pdf

32. Thakur, J.S., Jeet, G., Nangia, R., Singh, D., Grover, S., \&Lyngdoh, T., et al. (2019). Non-communicable diseases risk factors and their determinants: A cross-sectional state-wide STEPS survey, Haryana, North India. PLoS One, 14(11), 0208872.

33. Deepa, M.,Pradeepa, R., Anjana, R.M., \& Mohan, V. (2011). Noncommunicable diseases risk factor surveillance: experience and challenge from India. Indian Journal of Community Medicine: Official 
Publication of Indian Association of Preventive \& Social Medicine, 36(Suppl1), S50.

34. Sivanantham, P., Sahoo, J., Lakshminarayanan, S., Bobby, Z., \&Kar, S.S. (2021). Profile of risk factors for Non-Communicable Diseases (NCDs) in a highly urbanized district of India: Findings from Puducherry district-wide STEPS Survey, 2019-20. PloS One, 16(1), e0245254.

35. Bhagyalaxmi, A., Atul, T. \&Shikha, J. (2013). Prevalence of risk factors of non-communicable diseases in a District of Gujarat, India. Journal of Health, Population, and Nutrition, 31(1), 78-85.

36. Anjana, R.M., Pradeepa, R., Deepa, M., Datta, M., Sudha, V., \&Unnikrishnan, R. (2011). Prevalence of diabetes and prediabetes (impaired fasting glucose and/or impaired glucose tolerance) in urban and rural India: Phase I results of the Indian Council of Medical Research-INdiaDIABetes (ICMR-INDIAB) study. Diabetologia, 54(12), 3022-3027.

37. Shah, B., \&Mathur, P. (2010). Surveillance of cardiovascular disease risk factors in India: the need \& scope. The Indian Journal of Medical Research, 132(5), 634-642.

38. Jayamani, V., Gopichandran, V., Lee, P., Alexander, G., Christopher, S., \&Prasad, J.H. (2013). Diet and physical activity among women in urban and rural areas in South India: A community based comparative survey. Journal of Family Medicine and Primary Care, 2(4), 334-338.

39. Mathew, A., Gajalakshmi, V., Rajan, B., Kanimozhi, V.C., Brennan, P., \&Binukumar, B.P., et al. (2009). Physical activity levels among urban and rural women in south India and the risk of breast cancer: a case-control study. European Journal of Cancer Prevention, 18(5), 368-376.

40. Tripathy, J.P., Thakur, J.S., Jeet, G., Chawla, S., Jain, S. and Prasad, R.(2016). Urban rural differences in diet, physical activity and obesity in India: are we witnessing the great Indian equalisation? Results from a cross-sectional STEPS survey. BMC Public Health, 16(1), 1-10.

41. Devamani, C.S., Oommen, A.M., Mini, G.K., Abraham, V.J. \& George, K. (2019). Levels of physical inactivity in rural and urban Tamil Nadu, India: a cross-sectional study. Journal of Clinical and Preventive Cardiology, 8(1), 13-17.

42. Newtonraj, A., Vincent, A., Gowtham, P.J., Haritha, S.,\&llaveyini, S. (2019). Level of insufficient physical activity among adults in a rural area of South India: A population-based cross-sectional study. Journal of Current Research in Scientific Medicine, 5(2), 105-109.

43. Guthold, R., Stevens, G.A., Riley, L.M., \& Bull, F.C. (2018). Worldwide trends in insufficient physical activity from 2001 to 2016: a pooled analysis of 358 population-based surveys with 1. 9 million participants. The Lancet Global Health, 6(10), e1077-e1086.

44. Krishnan, A., Asadullah, M.D., Roy, A., Praveen, P.A., Singh, K., \&Amarchand, R., et al. (2020). Change in prevalence of Coronary Heart Disease and its risk between 1991-94 to 2010-12 among rural and urban population of National Capital Region, Delhi. Indian Heart Journal, 72(5), 403-409.

45. Pradeepa, R., Anjana, R.M., Joshi, S.R., Bhansali, A., Deepa, M., \&Joshi, P.P., et al.(2015). Prevalence of generalized \& abdominal obesity in urban \& rural India-the ICMR-INDIAB Study (Phase-I)[ICMRINDIAB-3]. The Indian Journal of Medical Research, 142(2), 139.

46. Mishra, V. (2004). Effect of obesity on asthma among adult Indian women. International Journal of Obesity, 28(8), 1048-1058. 
47. Farajian, P., Renti, E. \&Manios, Y.(2008). Obesity indices in relation to cardiovascular disease risk factors among young adult female students. British Journal of Nutrition, 99(4), 918-924.

48. Kalra, S., \&Unnikrishnan, A.G.(2012). Obesity in India: The weight of the nation. Journal of Medical Nutrition and Nutraceuticals, 1(1), 37-41.

49. Misra, A., Pandey, R.M., Rama Devi, J., Sharma, R., Vikram, N.K., \& Khanna, N.(2001). High prevalence of diabetes, obesity and dyslipidaemia in urban slum population in northern India. International Journal of Obesity, 25(11), 1722-1729.

50. Darsini, D., Hamidah, H., Notobroto, H.B., \&Cahyono, E.A.(2020). Health risks associated with high waist circumference: A systematic review. Journal of Public Health Research, 9(2).

51. Fauziana, R., Jeyagurunathan, A., Abdin, E., Vaingankar, J., Sagayadevan, V., \&Shafie, S., et al.(2016). Body mass index, waist-hip ratio and risk of chronic medical condition in the elderly population: results from the Well-being of the Singapore Elderly (WiSE) Study. BMC Geriatrics, 16(1), 1-9.

52. Midha, T., Krishna, V., Nath, B., Kumari, R., Rao, Y.K., \& Pandey, U., et al. (2014). Cut-off of body mass index and waist circumference to predict hypertension in Indian adults. World Journal of Clinical Cases: WJCC, 2(7), 272-278.

53. Malshe, S.D., \&Udipi, S.A. (2017). Waist-to-height ratio in Indian women: comparison with traditional indices of obesity, association with inflammatory biomarkers and lipid profile. Asia Pacific Journal of Public Health, 29(5), 411-421.

54. Bhattacharya, K., Sengupta, P., Dutta, S., Chaudhuri, P., Das Mukhopadhyay, L., \&Syamal, A.K.(2021). Waist-to-height ratio and BMI as predictive markers for insulin resistance in women with PCOS in Kolkata, India. Endocrine, 72(1), 86-95.

55. Vikram, N.K., Latifi, A.N., Misra, A., Luthra, K., Bhatt, S.P., \&Guleria, R., et al. (2016). Waist-to-height ratio compared to standard obesity measures as predictor of cardiometabolic risk factors in Asian Indians in North India. Metabolic Syndrome and Related Disorders, 14(10), 492-499.

56. Bhattacharya, K., \&Bhaduri, D.(2018). Assessment of physical and physiological parameters among the male and female bakery workers from Palpa district of democratic Nepal.International Journalof Researchin Pharmacy and Science,9(1), 226-235.

57. Bhattacharya, K., Bhattacharya, S., Sengupta, P., Dutta, S., Choudhuri, G.R.,\&Mukhopadhyay, L.D. (2021). Coronavirus disease 2019 (COVID-19) and Pregnancy. Biomedical and Pharmacology Journal, 14(3), 1161-1175.

58. Bhattacharya, K., Sengupta, P., Dutta, S. \& Bhattacharya, S. (2020). Pathophysiology of obesity: endocrine, inflammatory and neural regulators. Research Journal of Pharmacy and Technology, 13(9), 4469-4478.

\section{Figures}




\section{Percentage of inactivity in leisure domain (Age wise)}

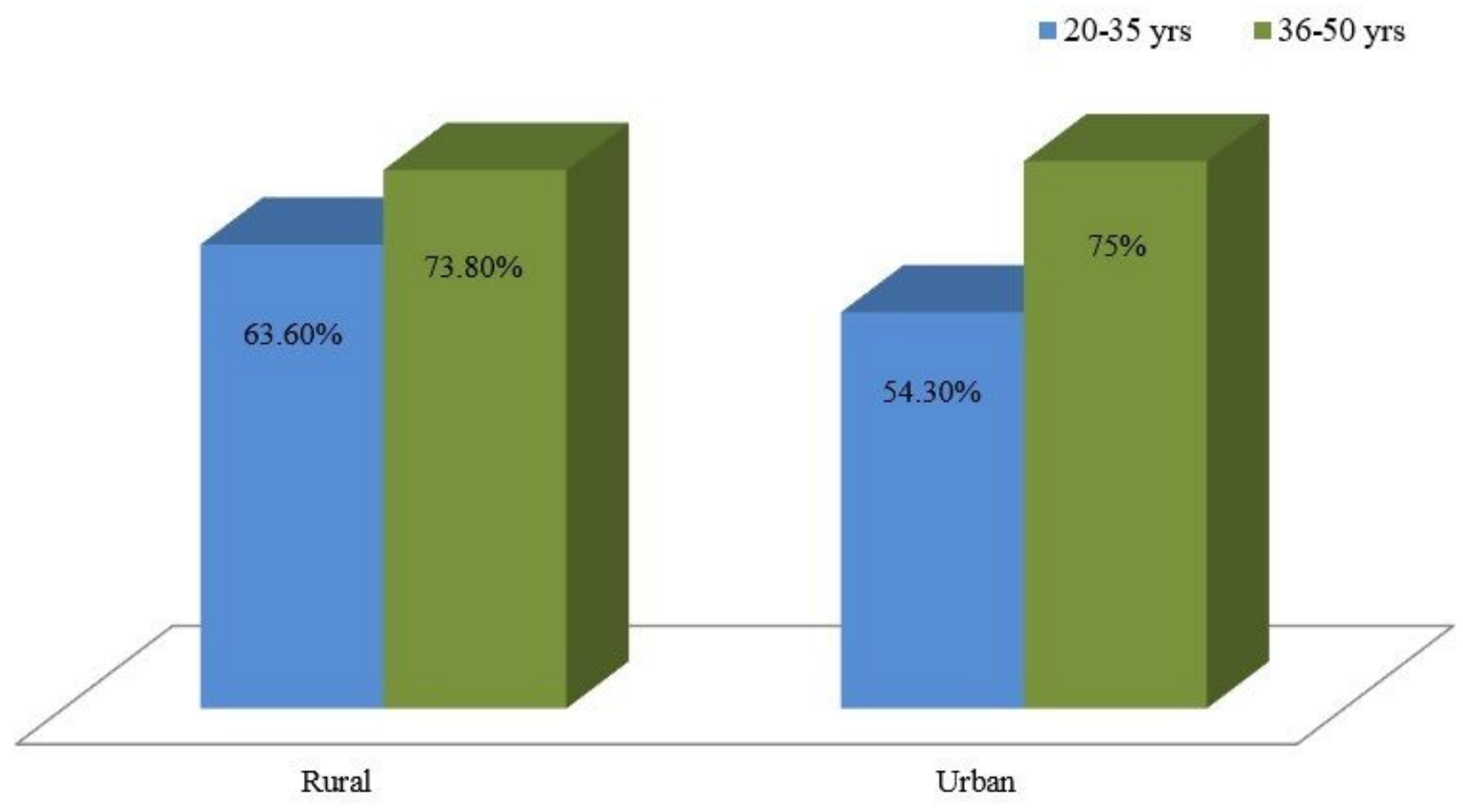

Figure 1

Mean percentage of energy derived from nutrients 


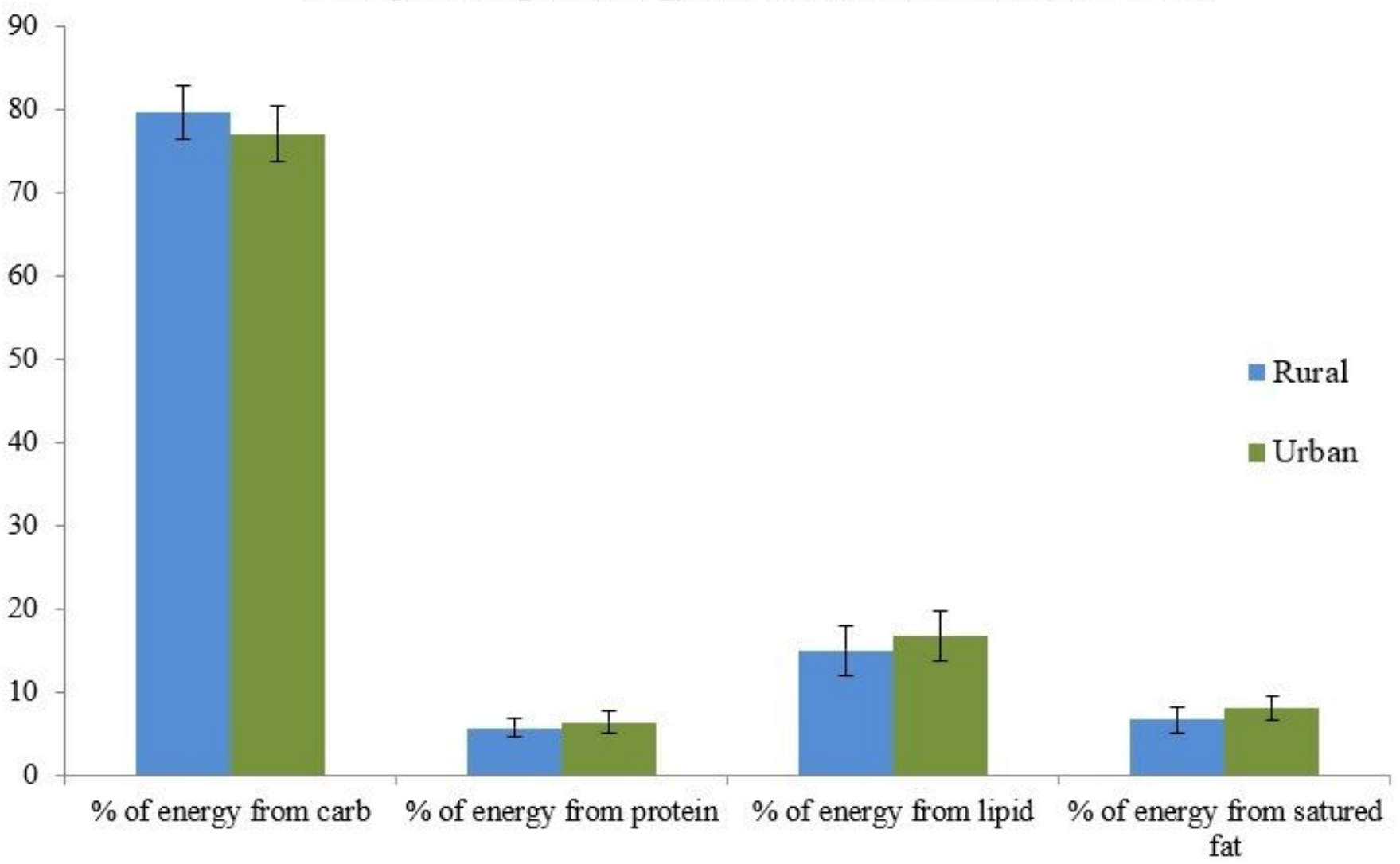

Figure 2

Percentage of inactivity in leisure domain (age wise) 